\title{
"YES, NÓS TEMOS BANANAS!" PRAIAS, CONDOMÍNIOS FECHADOS, RESORTS E PROBLEMAS SÓCIO- AMBIENTAIS ${ }^{\prime}$
}

\author{
ESTER LIMONAD \\ Universidade Federal Fluminense
}

Yes, nós temos bananas

Bananas pra dar e vender (...)

Pra todo mundo (...)

Bananas para quem quiser

Alberto Ribeiro e João de Barro (1937)

A proliferação de condomínios, resorts e clubes turísticos na orla do litoral brasileiro e o aumento do turismo internacional contribuem para cunhar uma nova imagem e inserção do Brasil na divisão internacional do trabalho enquanto paraíso tropical para o turismo, lazer e last but not least, local para uma segunda residência a seis horas e meia de viagem do continente europeu, conforme apregoava uma propaganda de sítios de segunda residência nas cercanias de Fortaleza, no Ceará, em uma revista de bordo da companhia aérea $\mathrm{TAP}^{2}$ em janeiro de 2006. De certa forma esta promoção internacional do Brasil e seu loteamento no exterior, em particular na Espanha e Portugal, remete à marchinha pré-tropicalista de Alberto Ribeiro e João de Barro, Yes, Nós Temos Bananas, que serve de título e epígrafe a este ensaio. Quando esta marchinha foi escrita o Brasil aparecia como uma república de bananas, uma economia agro-exportadora tropical atrasada. Passaram-se os anos, o país se desenvolveu e alcançou um patamar intermediário de desenvolvimento entre os países centrais avançados e os países latino-americanos.

1. Esta é uma versão revisada e ampliada do trabalho apresentado e publicado nos Anais do XII Encontro Anual da Associação Nacional de Pesquisa e Pós-Graduação em Planejamento Urbano e Regional (ANPUR), realizado de 21 a 25 de maio de 2007, na Universidade Federal do Pará, em Belém do Pará.

2. Transportes Aéreos de Portugal. 
Agora o que é comercializado "para dar e vender, pra todo mundo e para quem quiser", são as áreas litorâneas do Nordeste do Brasil. E, por vezes as áreas nem tão litorâneas assim, como ilustra a foto 1 .

O crescimento das atividades de turismo e veraneio contribui já há um certo tempo para converter em objeto de consumo uma série de lugares, com destaque para a orla litorânea de países de clima ameno, tropicais e equatoriais. A orla litorânea brasileira, com $8.698 \mathrm{~km}$ de extensão, uma das mais extensas orlas litorâneas tropicais do mundo, não constitui uma exceção nesse sentido.

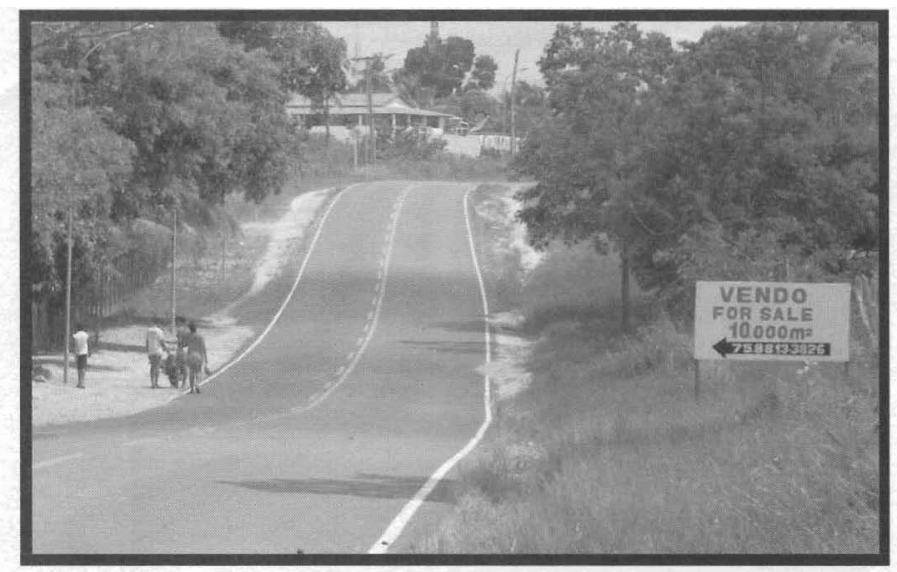

Foto 1. Estrada de acesso da rodovia estadual BA099 ao município de Conde, Bahia, a $175 \mathrm{~km}$ de Salvador. (Foto: Ester Limonad, 2006)

É inegável o desenvolvimento do turismo internacional no Brasil nos últimos anos. Entre os fatores internacionais que teriam contribuído para a expansão do turismo para além dos destinos convencionais do Sudeste do Brasil, estariam: o aumento da tensão política, nos países da África do Norte, do Oriente Médio; os problemas internos na Turquia; a tensão entre os países que compunham a Iugoslávia, aos quais se somam as catástrofes naturais, com destaque para as monções, enchentes e tsunamis na Ásia, além dos furacões e eventuais terremotos no México e na América Central.

Muitas vezes, em nome do desenvolvimento local sustentável, da geração de empregos e da inserção nos fluxos produtivos, vários municípios litorâneos, quando não os governos estaduais secundados pelo governo federal, abrem exceções ou encontram soluções de compromisso com promotores imobiliários, incorporadores e grupos hoteleiros e grupos turísticos de porte internacional. Tais "soluções" contribuem para permitir a implantação de resorts, hotéis de luxo, marinas e condomínios fechados nas áreas litorâneas. Resulta daí uma expansão 
geográfica indiscriminada das atividades de turismo-veraneio que, somada à multiplicação exponencial de condomínios de segunda residência em áreas litorâneas, coloca em risco a diversidade de um dos mais ricos conjuntos de ecossistemas costeiros tropicais do mundo.

Embora o Brasil possua uma das mais avançadas legislações ambientais e um programa de proteção da orla litorânea (BRASIL, 2004), implementado pelo Ministério do Meio Ambiente com uma orientação direcionada a preservar a diversidade dos ecossistemas costeiros, as diretrizes legais não soem ser cumpridas por motivos variados: falta de recursos e de capacidade de fiscalização, utilização de subterfúgios para provar que a implantação é anterior à legislação (coqueiros, lavouras), acordos entre prefeituras e promotores imobiliários em flagrante desrespeito à legislação ambiental. Mais do que seria desejável a "exceção é a regra".

A intenção deste ensaio é levantar a extensão e as características da atual ocupação costeira por parte de condomínios, resorts e aglomerados urbanos em um trecho específico da orla litorânea do Nordeste do Brasil: a Costa dos Coqueiros ao norte da região metropolitana de Salvador na Bahia, e proceder a algumas breves considerações sobre os impactos sócio-ambientais resultantes e buscar propor elementos que subsidiem ações integradas de planejamento e desenvolvimento regional para a área.

\section{Cuando calienta el sol, ivamos a la playa! ${ }^{3}$}

As áreas litorâneas, em diversas partes do mundo, tendem a apresentar historicamente uma maior concentração de população e de atividades produtivas. Isto é mais evidente em países de formação colonial, como o Brasil, em que os aglomerados e portos litorâneos serviam para escoar a produção para a metrópole reinol. Em decorrência das estruturas coloniais herdadas é na área costeira brasileira que se encontra a maior concentração de áreas urbanas, que congregam uma ampla gama de atividades de distintas esferas de (re) produção, com as respectivas instalações e infraestruturas de suporte.

A partir do primeiro quartel do século XX, intensificou-se a ocupação das orlas litorâneas em diversas partes do mundo em razão de uma nova moda: bronzearse ao sol. Moda esta atribuída por alguns a Coco Chanel que, por ocasião do lançamento de sua coleção de alta-costura, ao inicio da década de 1920, apareceu em Paris com a pele tostada, após uma temporada de férias a bordo de um iate nas águas do Mediterrâneo. Fato ou lenda, a questão é que, nunca mais a alva tez das jovens casadoiras de "boa família", nem a de suas famílias foi a mesma. E tampouco os balneários permaneceram os mesmos. A partir da década de 1930, verifica-sé

\footnotetext{
3. Quando o sol esquenta, vamos à praia!
} 
uma crescente ocupação das praias e balneários em diversas partes do mundo. Veranear tornou-se sinônimo de bronzear-se e ir à praia, e passou a integrar de forma incisiva o universo dos destinos turísticos nacionais e internacionais em todo o mundo. Quanto mais se disseminava esta moda, mais exíguos os trajes de banho. Corpos bronzeados converteram-se em sinal de saúde e vigor, assim, com o inicio das estações mais quentes ao invés de se dirigir a áreas com clima mais ameno e fresco, multidões passaram a se deslocar rumo às praias para descansar e adquirir a cor desejada...

A crescente inserção do Brasil no turismo internacional contribuiu para acelerar a ocupação e adensamento de locais na costa antes isolados e quase intocados. Assim, nos últimos anos vieram se somar às estruturas e instalações pré-existentes outras, relacionadas à introdução e desenvolvimento em áreas antes preservadas de uma ampla gama de novas atividades produtivas, que abrangem a exploração de petróleo e gás natural em alto-mar, bem como atividades de suporte ao turismo e ao veraneio. O desenvolvimento de tais atividades compreende desde a implantação localizada de instalações industriais de suporte a operações em alto-mar para a exploração, beneficiamento e armazenamento de petróleo e gás natural, implantação de aglomerados residenciais para os trabalhadores até a proliferação dispersa de condomínios de primeira e segunda-residência, resorts internacionais, marinas e instalações para a realização de atividades desportivas.

Nas áreas litorâneas do Brasil, as atividades produtivas e suas estruturas de suporte encontram-se implantadas em pontos estratégicos da costa, em um padrão espacial caracterizado pela ocupação intensiva do solo e concentração espacial de instalações, que abrigam diversos tipos de atividades e serviços. Por sua vez, o desenvolvimento de atividades turísticas, de atividades de veraneio e a implantação de condomínios de segunda residência respondem por uma ocupação pulverizada e segmentada, usualmente caracterizada como urbanização extensiva e/ou dispersa (MONTE-MOR, 1994; LIMONAD, 1996 e COSTA et al., 2006). Resulta daí uma ocupação desordenada de aglomerados de caráter urbano dispersos, em que se verifica a multiplicação irregular de edificações residenciais e de serviços sem infraestruturas de saneamento, que além de avançar sobre os mangues, restingas e lagoas, aí lançam esgoto in-natura, queimam a mata para limpar as áreas para construir e implantar jardins, o que acarreta uma crescente degradação ambiental com a redução das praias, assoreamento dos rios, contaminação dos lençóis freáticos e redução dos recursos naturais.

Desde a instalação dos Clubes, Mediterranee $e^{4}$ na década de 1980, na Bahia e no Rio de Janeiro, multiplicaram-se os complexos hoteleiros e resorts internacionais no litoral brasileiro. A implantação destas instalações destinadas a promover e acolher o turismo nacional e internacional, em áreas antes voltadaś

${ }^{4}$ Acessivel em http://www.clubmed.com.br/, em 12/2006 
para atividades de cunho agrário, via de regra, tende a provocar a extinção da pesca artesanal e expropriação de pequenos produtores, com a cooptação de parcelas destes grupos sociais para a prestação de serviços no âmbito turístico, como foi o caso da orla da Baia da Ilha Grande, no Estado do Rio de Janeiro (BERTONCELLO, 1992 e LIMONAD, 1996).

Neste inicio de milênio, o litoral do Nordeste é o que desponta com maior densidade de ocupação, seguido pelo litoral de Santa Catarina (MORAES, 2004). Atualmente, é no Nordeste que se encontra, também, a maior concentração de resorts e complexos hoteleiros voltados para o turismo internacional. Atualmente os resorts estendem-se pelo litoral nordestino com diversas interrupções, desde a costa do descobrimento no sul da Bahia, até as cercanias de Fortaleza no Ceará. Destacam-se, entre eles, os resorts internacionais da ilha de Comandatuba ${ }^{5}$ na costa sul da Bahia; o Club Mediterranée em Itaparica na Baia de Todos os Santos; o Ecoresort e spa da Praia do Forte ${ }^{6}$ do grupo português Espírito Santo Hotels (GESH), a Costa do Sauípe ${ }^{7}$ do Fundo de Pensão do Banco do Brasil (PREVI), aos quais vêm se somar a Reserva Imbassai ${ }^{8}$ do grupo português Reta Atlântico $\mathrm{e}$ o Iberostar resort ${ }^{I 0}$ da rede espanhola Iberostar, estes últimos ao norte de Salvador, em localidades vizinhas do município de Mata de São João, ao longo da "Linha Verde" (rodovia estadual BA-099) na chamada Costa dos Coqueiros. A estes se soma, mais ao norte, por diversos grupos hoteleiros internacionais, a exploração turística de Maragogi ${ }^{11}$ (Alagoas), Porto de Galinhas ${ }^{12}$ (Pernambuco) e da Praia da Pipa $^{13}$ (Rio Grande do Norte), entre outras tantas localidades. Vários destes resorts, hotéis e condomínios situam-se em áreas de preservação ambiental e/ou de reprodução de tartarugas marinhas e golfinhos, como a Praia do Forte, Porto Galinhas e a Praia da Pipa.

${ }^{5}$ Acessivel em http://www.comandatuba.com.br/, em 12/2006.

${ }^{6}$ Acessível em http://www.praiadoforteecoresort.com.br/port/index.asp, em 12/2006.

${ }^{7}$ Acessivel em http://www.costadosauipe.com.br/index.php?idioma=1\&intro=ok, em 12/ 2006.

${ }^{8}$ Acessível em http://www.reservaimbassai.com, em 12/2006.

${ }^{9}$ Acessível em http://www.retaatlantico.com/htm/homepage, em 12/2006.

${ }^{10}$ Acessivel em http://www.iberostar.com, em 12/2006.

"Onde se encontram dois resorts de médio porte o Salinas do Maragogi (acessível em http://www.salinas.com.br/estrutura.htm, em 12/2006) e o Miramar Maragogi, pertencente a um grupo português (acessível em http://www.miramarmaragogiresort.com/villas/ index.htm eco, em 12/2006)

12 Acessível em http://www.portogalinhas.com.br/, em 12/2006. Em Porto Galinhas' encontra-se o Enotel Resort e Spa do Grupo Português Estevão Neves com 7 hectares a $57 \mathrm{~km}$ de Recife (Acessível em http://www.enotel.com.br/resort/resort.php, em 12/2006). ${ }^{13}$ Acessível em http://www.pipa.com.br/conteudo/informativo/conheca.html, em 12/2006. 
Para recepcionar e viabilizar o turismo internacional de grande porte, o governo federal, sob as duas gestões do Presidente Fernando Henrique Cardoso, no âmbito dos Programas Federais "Brasil em Ação ${ }^{\mathbf{1 4} "}$ e "Avança Brasil" (BRASIL, 2002, p. 13) implementou o Programa de Desenvolvimento do Turismo (Prodetur ${ }^{15}$ ). Este Programa tinha por meta criar condições gerais e infraestruturas diversas de suporte para implementar o turismo em moldes empresariais em nove Estados Nordestinos, além do norte de Minas Gerais e Espírito Santo. As ações implementadas pelo governo federal compreenderam, então, investimentos para (LIMONAD, 2006):

tornar internacionais os aeroportos locais das capitais nordestinas, que implicou na construção ou reforma destes aeroportos e adequação de seus equipamentos e instalações às necessidades impostas pelo turismo internacional;

renovar as rodovias de acesso aos resorts e possibilitar a implantação de serviços exclusivos de transporte rodoviário entre os aeroportos e as áreas turísticas;

a concessão de exploração de rotas aéreas internacionais regulares a diversas companhias aéreas para conectar as capitais do Nordeste a algumas cidades européias.

Tais ações colocaram o Nordeste do Brasil ao alcance das classes médias européias, principalmente com o aumento do número de vôos diretos entre o Nordeste e as capitais européias, que contam com ao menos três vôos diretos por semana da companhia aérea portuguesa TAP, além dos vôos da companhia aérea Ibéria, com vôos regulares diretos entre as cidades do Nordeste e Madrid, bem como vôos fretados da Alemanha e de outros países europeus.

\section{O que é que a Bahia tem? ${ }^{16}$}

O Litoral Norte da Bahia, nos últimos cinco anos tornou-se um dos maiores pólos turísticos em crescimento do Brasil, considerando o volume de investimentos nacionais e internacionais e da implantação de condições gerais para abrigar o

${ }^{14}$ Acessível em https://www.planalto.gov.br/publi_04/COLECAO/BRAIN.HTM, em 12/ 2006.

15 "O Programa de Desenvolvimento do Turismo no Nordeste (PRODETUR/NE) é um programa de crédito para o setor público (Estados e Municípios) que foi concebido tanto para criar condições favoráveis à expansão e melhoria da qualidade da atividade turística na Região Nordeste, quanto para melhorar a qualidade de vida das populações residentes nas áreas beneficiadas. O PRODETUR/NE é financiado com recursos do BID e tem o Banco do Nordeste como Órgão Executor." (acessível em http://www.bnb.gov.br/ content/ aplicacao/PRODETUR/Apresentacao/gerados/apresentacao.asp, em 12/2006) 
turismo de porte internacional ${ }^{17}$. Esta área denominada de Costa dos Coqueiros, estende-se ao longo da Estrada do Coco e de seu prolongamento, a Linha Verde (BA-099), desde a região metropolitana de Salvador até a divisa com o estado de Sergipe, e compreende a Área de Proteção Ambiental (APA) Litoral Norte ${ }^{18}$ e a APA Mangue Seco. Interliga, assim, a área litorânea dos municípios de Camaçari e Lauro de Freitas, na região metropolitana de Salvador, aos povoados litorâneos dos municípios de Mata de São João, Entre Rios, Esplanada, Conde e Jandaíra (ver Mapa 1). Estes cinco municípios são de pequeno porte, com menos de trinta e cinco mil habitantes (ver tabela 1), e sua população encontra-se distribuída em pequenos povoados. Até 1992, todos estes municípios, com exceção de Conde, embora estivessem próximos a Salvador, eram polarizados pelo município de Alagoinhas e estruturaram-se ao longo das rodovias BA-093 e BR-101, enquanto a orla permaneceu isolada (BAHIA, 2001:12).

A Costa dos Coqueiros, ao longo de seus 193 quilômetros de extensão, é recortada por diversos rios e riachos, que deságuam no mar por entre um vasto cordão de brancas dunas, que acompanha a costa. Aí se encontra uma ampla variedade de ecossistemas, que abrangem desde remanescentes de Mata Atlântica, restingas, dunas, coqueirais, brejos, lagoas ferruginosas de águas escuras até manguezais e recifes de coral, que além de abrigar um leque diversificado de espécies vegetais e animais, constituem nichos reprodutivos para diferentes espécies de animais (tartarugas, golfinhos e baleias jubarte em particular).

\footnotetext{
16. Corruptela do título da canção de Dorival Caymmi: $O$ que é que a baiana tem?. Foi realizado um primeiro trabalho de campo em 06/2005, ao qual se seguiu um trabalho mais extenso em 12/2006, em que se percorreu a Linha Verde de Salvador ao município de Conde. Então, foram visitados e realizadas entrevistas no Ecoresort da Praia do Forte, Iberostar Resort, Reserva Imbassaí e Costa do Sauípe, e em outros hotéis, postos turísticos, stands de corretagem, com funcionários de resorts, hotéis e incorporadoras, assim como com moradores e trabalhadores de vários povoados da Costa dos Coqueiros.

17. Ver a respeito dados do Prodetur-BA (Acessível em http://www.sct.ba.gov.br/ prodetur_historico.asp, em 12/2006)

18. Em 1992, com o objetivo de proteger o patrimônio ambiental desta faixa litorânea foi criada a Área de Proteção Ambiental (APA) Litoral Norte da Bahia, que compreende parte dos municípios de Mata de São João, Entre Rios, Esplanada, Conde e Jandaíra, no extremo norte do Litoral encontrase a APA Mangue Seco.
} 


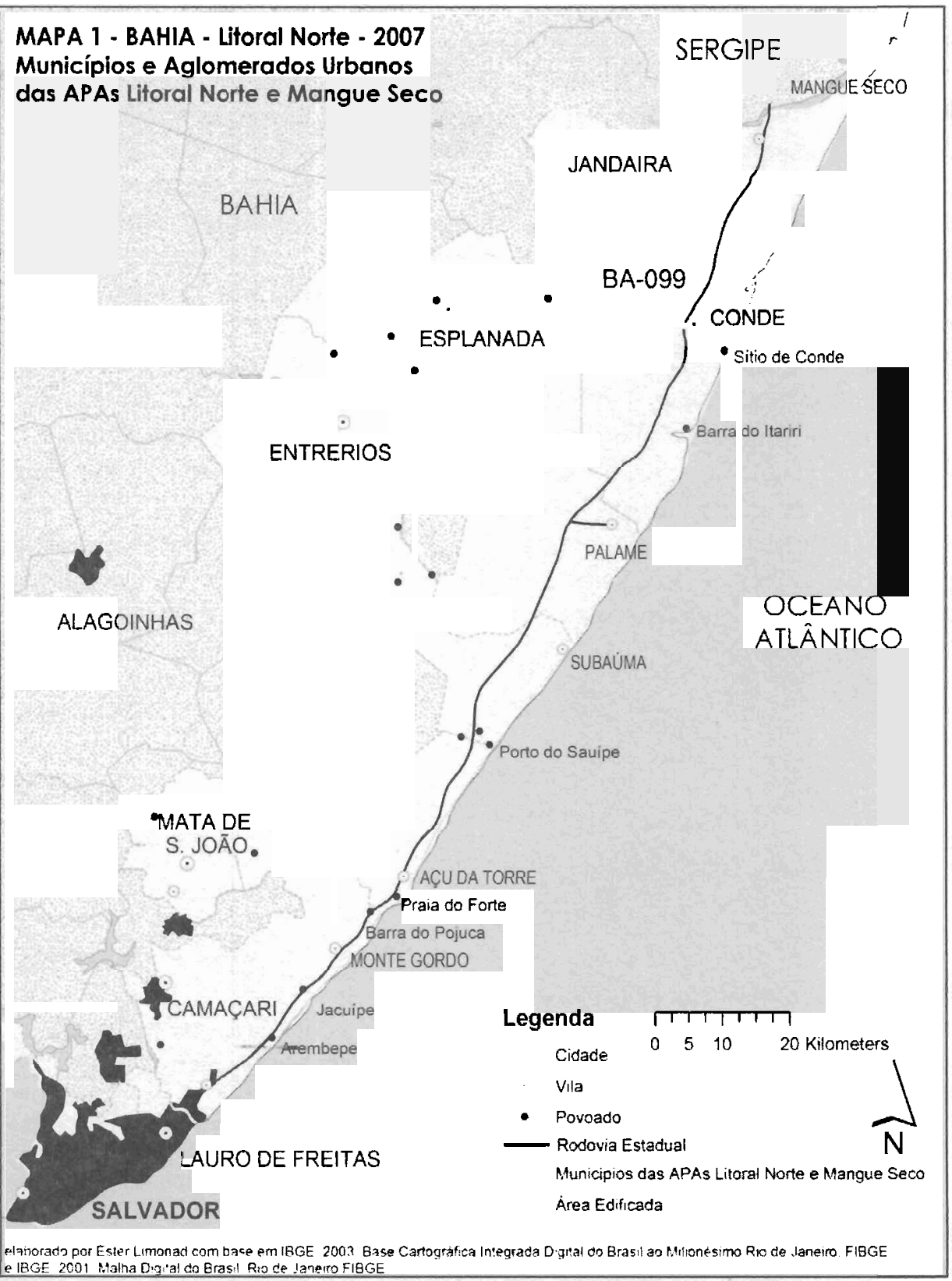


A desarticulação das relações tradicionais de produção, pesca artesanal e lavouras de subsistência, na Costa dos Coqueiros, inicia-se na década de 1970 com a vinda de várias empresas de reflorestamento (idem, pp. 10-12). A implantação de florestas homogêneas em grandes extensões de terra contribuiu para aprofundar a concentração fundiária com o assalariamento dos pequenos proprietários, para substituir as lavouras tradicionais por plantações de pinus e eucaliptos e para induzir uma urbanização forçada nos principais aglomerados urbanos. Atualmente, as plantações de eucaliptos das empresas de papel estendem-se, principalmente ao norte de Porto Sauípe, nos municípios de Entre Rios, Esplanada e Conde, em ambos lados da "Linha Verde", em um continuum quase ininterrupto.

Neste contexto as atividades de turismo e veraneio no litoral norte baiano eram acanhadas e de cunho local, com impactos ambientais previsíveis e controláveis, com exceção de alguns poucos casos isolados, como a Praia do Forte. Entre os fatores que contribuíram para a expansão da ocupação litorânea pelos condomínios, atividades de turismo e mega-resorts foi o fato de quase todos municípios da APA-Litoral Norte, com exceção de Conde, possuírem a sede ao menos a cinqüenta quilômetros da costa, e por apresentarem uma concentração prévia da população nos pequenos povoados interiorizados, como se pode perceber pela distribuição da população na tabela 1 abaixo, em um período anterior à implantação dos resorts em Mata de São João e no inicio do Prodetur - I (19941998).

Tabela 1: BAHIA - POPULAÇÃO E DOMICÍLIOS NA APA LITORAL NORTE - 1996-2000

\begin{tabular}{lcrrr}
\hline Municipio & \multicolumn{2}{c}{ APA LITORAL NORTE } & \multicolumn{2}{c}{ Município } \\
& Domicílios & População & População & \% População na APA \\
Mata de São João & 1.338 & 5.666 & 32.452 & 17,46 \\
Entre Rios & 807 & 3.578 & 32.380 & 11,05 \\
Esplanada & 1.002 & 4.583 & 25.417 & 18,03 \\
Conde & 3.234 & 15.158 & 18.695 & 81,08 \\
\hline
\end{tabular}

Extraído de BAHIA, 200I - elaborado a partir de dados do PNAD-IBGE (1996) e mapas censitários do IBGE (I990)

Este quadro se altera, em 1992, com a abertura da Linha Verde (BA-099) e, posteriormente, com a implementação do Prodetur-Bahia ${ }^{19}$, em 1995. Cerca de um terço dos recursos do Prodetur-Nordeste ${ }^{20}$, implementado pelo Banco do Nordeste do Brasil financiado pelo Banco Interamericano de Desenvolvimento (BID) e pelo Banco Nacional de Desenvolvimento Social (BNDES) em um total

\footnotetext{
19. Acessível em http://www.sct.ba.gov.br/prodetur_historico.asp, em 12/2006

20. “O Programa reúne cerca de 500 projetos. Para a sua execução, estão disponíveis recursos totais de US $\$ 800$ milhões. Destes, US $\$ 400$ milhões são provenientes do BID - Banco Interamericano de Desenvolvimento, sendo o Banco do Nordeste do Brasil (BNB) seu agente repassador. A regulamentação dessa linha de financiamento previu em sua concepção original uma contrapartida de recursos próprios ao nível de 50\%. O contrato entre o BID e o BNB foi firmado em 12 de dezembro de 1994, pelo prazo de 25 anos". (Acessível em http://www.finame.gov.br/conhecimento/ setorial/get4is06.pdf, em 12/2006)
} 
de 215 milhões de dólares, destinou-se ao desenvolvimento do turismo no estado da Bahia, em particular para a área de planejamento turístico de Salvador e seu entorno, que englobou a Costa dos Coqueiros. Mais da metade dos investimentos do Prodetur-Bahia destinou-se à modernização do aeroporto internacional de Salvador (Aeroporto Deputado Luis Eduardo Magalhães), em um montante de 115 milhões de dólares, e à implantação de infraestrutura de saneamento básico no município de Mata de São João, em um total de 5,5 milhões de dólares, nas localidades de Praia do Forte e Costa do Sauípe ${ }^{21}$, onde se encontram atualmente quatro mega-resorts de porte internacional.

As obras do Prodetur-Bahia somadas à implantação e duplicação da "Linha Verde" (BA-099), não só tiraram do isolamento as praias e diversas povoações litorâneas da Costa dos Coqueiros, como também as tornaram acessíveis aos moradores de Salvador, aos promotores imobiliários e aos mega-empreendimentos de turismo de grande porte internacional. O próprio relatório do Prodetur I(BNDES, 1999) reconhece que em sua primeira fase de implementação "o mais importante projeto alavancado para a Bahia foi o Complexo Turístico de Sauípe", onde foram investidos US $\$ 200$ milhões, e cujas vias de acesso e obras de infra-estrutura foram concluídas em 1996.

Em decorrência destes investimentos, do desenvolvimento do turismo e do aquecimento do mercado imobiliário transformou-se radicalmente quase toda a faixa litorânea, que compreende a Área de Proteção Ambiental (APA) Litoral Norte, em particular a porção que se estende da região metropolitana até a divisa do município de Mata de São João (Praia do Forte, Costa do Sauípe e Imbassaí) até o município de Entre Rios (Porto Sauípe, Massarandupió e Subaúma). Mais adiante, na APA Mangue Seco, também se pode observar transformações na área costeira do município de Conde, especialmente entre Sítio do Conde e Barra do Itariri, a cerca de 170 quilômetros de Salvador. Em muitas destas localidades, os diminutos povoados de pescadores ou de pequenos produtores rurais, até então relativamente preservados, cederam lugar e foram substituídos por condomínios de segunda residência, complexos hoteleiros e, como se isso não bastasse, resorts voltados para o turismo internacional.

Não obstante, todas as medidas tomadas e a "consciência ambiental e social" dos empreendimentos de grande porte, tende a se aprofundar a segregação sócio-espacial com o agravamento do quadro atual de pobreza. Ampliam-se, assim, as diferenças entre alguns dos povoados costeiros tomados pelo turismo, internacional e nacional de alta renda, equipados com infraestruturas de abastecimento, saneamento, comunicação e transportes, que contam com maiores oportunidades de emprego, e os povoados costeiros e do interior, sem infraestruturas

${ }^{21}$. Acessivel em http://www.sct.ba.gov.br/prodetur2.asp, em 12/2006. 
e sem serviços, que apenas contam como acesso com precárias estradas de terra, onde passou a residir a população local.

A pesquisa realizada in loco identificou quatro tipos principais de exploração turística:

a) Atividades de grande porte, direcionadas ao mercado internacional, concentradas em Mata de São João, onde se situam o Eco Resort da Praia do Forte do grupo português Espírito Santo Hotels; o Iberostar Resort ao lado da Praia do Forte, pertencente à mega-corporação espanhola de mesmo nome; a Reserva Imbassaí do grupo português Reta Atlântico S.A., vizinha ao povoado de Imbassaí, e o Complexo Costa do Sauípe, implantado pela Construtora Norberto Odebrecht e gerenciado pelo Fundo de Pensão do Banco do Brasil (PREVI), vizinho ao povoado de Porto Sauípe, na divisa com o município de Entre Rios.

b) Atividades de pequeno e médio porte, com foco no mercado turístico nacional (Sudeste, Sul e Centro-Oeste), em Imbassaí, Praia do Forte, em Mata de São João, e em Sítio do Conde e Barra do Itariri, em Conde;

c) Atividades com ênfase no mercado turístico local e regional (municípios vizinhos da Bahia e do Sergipe), nos povoados litorâneos de fácil acesso entre Porto Sauípe, no município de Entre Rios, e Mangue Seco, no município de Jandaíra, com destaque para Sítio do Conde, no município de Conde.

d) Atividades de baixo impacto e consumo especializado nos povoados de difícil acesso como Massarandupió (naturismo), no município de Entre Rios, Baixios de Palame, no município de Esplanada, e Barra de Itariri, no município de Conde.

O desenvolvimento destas atividades turísticas está relacionado a diferentes tipos de uso e ocupação do solo, com uma clara diferenciação espacial no tocante à distribuição das atividades produtivas e ocupação da mão de obra, como se assinala a seguir.

Os condomínios fechados de segunda residência e veraneio tendem a ocupar preferencialmente as áreas de restinga e dunas costeiras, em particular nas áreas próximas à região metropolitana, nos municípios de Lauro de Freitas e Camaçari, onde a estrutura fundiária é mais fragmentada. Predomina nestes condomínios, situados sobre as dunas, na porção leste do eixo viário, entre a orla e o eixo viário litorâneo, uma população flutuante de fim-de-semana, de média e alta renda, proveniente de Salvador. A implantação dos condomínios além de ser em áreas sem redes de esgoto; abre flancos para a proliferação de instalações comerciais e de serviços (lojas de materiais de construção e de jardim, bares, restaurantes, etc) edificadas de forma irregular. Esta ocupação ocorre em diversas localidades entre os povoados de Arembepe e Praia do Forte. E, ao avançar sobre os brejos, mangues e dunas costeiras não só deteriora os ecossistemas ao aterrar lagoas, erradicar a 
vegetação originária, extrair areia para a construção civil, despejar lixo e entulho nas áreas circunvizinhas, contaminar os lençóis freáticos, como também, contribui para acabar com os tradicionais meios de subsistência da população local.

Ainda no âmbito dos condomínios, é interessante notar que na franja metropolitana de Salvador, nos municípios de Lauro de Freitas e Camaçari, na porção oeste da "Estrada do Coco", encontram-se além dos condomínios de segunda residência, diversos condomínios de primeira residência, direcionados a um mercado de médio e alto poder aquisitivo, como é o caso do lançamento do condomínio Alphaville, nos mesmos moldes dos primeiros lançados em Barueri, na região metropolitana de São Paulo, na década de 1970. Aparentemente esta ocupação estaria, em parte, relacionada ao crescimento da atividade industrial no município de Camaçari, devido à implantação do complexo fabril da Ford.

As áreas litorâneas de fácil acesso pela "Linha Verde", que não possuem resorts ou condomínios fechados, tornam-se local de lazer de mochileiros nacionais e internacionais e de ônibus de "farofeiros". Como é o caso de Sítio do Conde, cuja praça nos fins de semana e feriados é tomada por ônibus fretados provenientes da região metropolitana de Salvador e de municípios do Sergipe. Entrevistas realizadas com diversos moradores das localidades de Conde, Sítio do Conde e Barra do Itariri, apontaram que este turismo de baixo consumo não é bem visto e aceito pela população local, que os vê como poluidores, baderneiros, criadores de conflitos e geradores de insegurança, que buscam se aproveitar dos habitantes dos povoados.

Os mega-resorts encontram-se instalados em áreas pertencentes a grandes propriedades rurais, como é o caso, por exemplo, da fazenda litorânea da Construtora Norberto Odebrecht, que conta com 1.760 hectares. Nestes megaresorts pode-se observar tentativas efetivas de preservação ambiental, em particular, pela não ocupação das dunas costeiras, pela preservação das lagoas ferruginosas e pela manutenção de áreas de preservação ambiental. Na Costa do Sauípe, inclusive, se mantém a vegetação original de restingas e dunas nos condomínios residenciais em construção. Além disso, contam com redes de esgotos, implantadas com verbas do Prodetur e mantidas pela Embasa (Empresa de Saneamento Básico do Estado da Bahia). Segundo o responsável técnico da Embasa ${ }^{22}$ na Costa dos Coqueiros, a rede de esgoto da Costa do Sauípe conta com mini-estações elevatórias que conduzem o esgoto para a estação de tratamento e posterior despejo no rio Santo Antônio. Este técnico assinalou, ainda, que o povoado da Praia do Forte possui o mesmo tipo de instalação, que também estaria previsto para os novos resorts em fase final de implantação (Reserva Imbassaí e Iberostar).

Verifica-se, assim, a partir de Salvador na direção norte até a divisa com o estado do Sergipe uma ocupação urbana incipiente e fragmentada, passível de ser

22. Entrevistado durante a pesquisa realizada na Costa do Sauípe, em 12/2006 
caracterizada no médio prazo como uma urbanização dispersa em duas direções. No eixo leste-oeste verifica-se um adensamento das sedes municipais e dos povoados interiorizados, situados à oeste da "Linha Verde", para onde se deslocou parte das populações locais de pescadores e caiçaras. Já no eixo norte-sul, de Salvador até o limite entre os municípios de Mata de São João e Entre Rios, na faixa litorânea, observa-se uma ocupação segmentada, com uma grande diversidade nos tipos de uso e ocupação do solo, que é acompanhada por uma intensa atividade imobiliária e da construção civil, com acentuado parcelamento do solo, devido à multiplicação de condomínios de segunda residência e a expansão de resorts e de complexos hoteleiros. Na orla litorânea do município de Mata de São João há uma maior intensidade de ocupação no povoado da Praia do Forte, onde coexistem distintos tipos de ocupação e uso do solo. Todavia, nos povoados de Imbassaí e Vila Sauípe prevalecem os mega-resorts internacionais implantados em terrenos de latifúndios pré-existentes. Ao norte de Mata de São João, nos municípios de Entre Rios, Esplanada, Conde e Jandaíra, predominam as grandes propriedades com plantações de eucaliptos e pinus, onde ainda se verificam atividades tradicionais relacionadas à silvicultura, agropecuária e pesca. Persistem ainda, em várias localidades enclaves da população local, que se dedica à pesca artesanal, como por exemplo no núcleo do povoado de Praia do Forte e em Imbassaí, município de Mata de São João, onde se situa o hotel resort Costa dos Coqueiros; em Porto Sauípe, em Entre Rios; e em Sítio do Conde, no município de Conde, onde se situam pousadas e hotéis de porte médio.

O peso das atividades turísticas, no entanto, já se faz sentir. Embora em Conde e Jandaíra estas atividades sejam de porte local e regional e possuam um alcance limitado, respondem pela absorção de uma parcela considerável da população dos povoados de Baixio, Sítio do Conde, Barra do Itariri e Mangue Seco, e isto se evidencia em uma diferenciação entre os povoados litorâneos e os do interior, que apresentam um nível maior de pobreza.

Observa-se, ainda, uma diferenciação na intensidade de ocupação, que praticamente divide a Costa dos Coqueiros em duas. Enquanto ao sul encontramse serviços diversos de suporte ao viajante, de Massarandupió, em Entre Rios, até a sede de Conde, em uma extensão de quase cem quilômetros, não há sequer um posto de gasolina ou de polícia rodoviária estadual ao longo da "Linha Verde". Coexistem, assim, ao longo da Costa dos Coqueiros, uma grande diversidade de usos e de atividades produtivas de cunho moderno e tradicional, que persistiram após a implantação das florestas homogêneas. A tendência, porém, é no médio prazo a população local dos municípios de Mata de São João e Entre Rios ser absorvida no mercado formal no âmbito da prestação de serviços às atividades de turismo e veraneio. 


\section{Welcome to Paradise ${ }^{23 !}$}

Atualmente encontram-se implantados e em funcionamento quatros megaresorts (ver Mapa 2) direcionados ao turismo internacional, todos concentrados no município de Mata de São João, entre o povoado da Praia do Forte e o Rio Sauípe, limite com o município de Entre Rios, em uma área de reprodução de tartarugas marinhas e baleias jubarte e onde se encontra a maior parte de Mata Atlântica remanescente da APA Litoral Norte do estado da Bahia. Aos quais veio se somar o Vila Galé Marés do grupo português Vila Galééc. Nesta área da Costa dos Coqueiros os principais modeladores do espaço são os grupos turísticos internacionais associados a promotores imobiliários nacionais e internacionais.

Cabe inicialmente fazer uma diferenciação entre hotéis e resorts. Embora, alguns hotéis de maior porte, situados em localidades mais ou menos isoladas, adotem a designação de resort, a pesquisa revelou que não passam de hotéis medianos com algumas instalações de lazer (piscina sauna, parque e churrasqueira). As diferenças entre os mega-resorts de porte internacional e os hotéis de médio porte, que por modismo adotam a designação de resort como o Resort Hotel Costa dos Coqueiros com 52 unidades de hospedagem, situado em Imbassaí, no município de Mata de São João, e o Hotel Itariri Resort com 20 unidades de hospedagem, no povoado de Barra de Itariri, no município de Conde, que contam com acesso precário através de estrada não pavimentada, reside não só na acessibilidade e na extensão dos terrenos em que se situam, mas na diversidade de serviços e equipamentos oferecidos em um local destinado ao repouso e ao lazer.

23. Bem Vindos ao Paraíso!

24. Acessível em http://www.vilagale.pt/homepage/grupo/grupo.php?, em 12/2006. 
"Yes, nós Temos Bananas!" Praias, Condomínios Fechados, Resorts e Problemas Sócio-ambientais

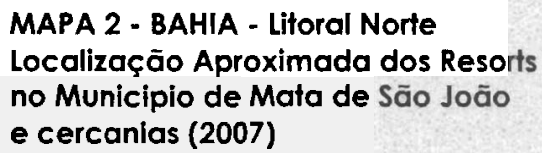

MAPA 2 - BAHIA - Litoral Norte Localizaçāo Aproximada dos Resorts no Municipio de Mata de São João

e cercanias (2007)

MATA DE S. JOĀO

-Porto do Sauipe

COSTA DO SAUIPE

(176 HA)

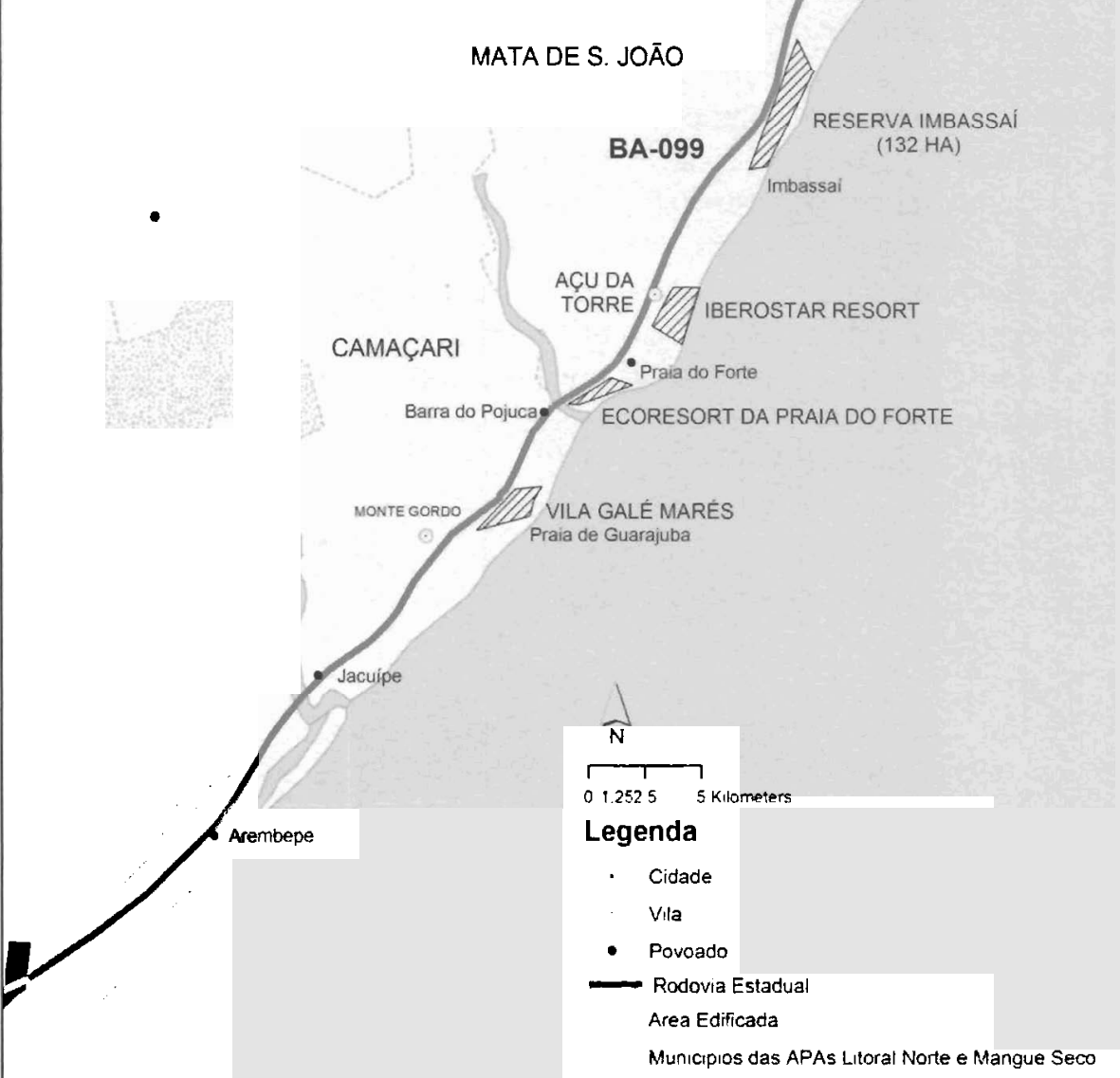

elaborado oor Ester Limorad com base em IBGE. 2003 Base Cartografica Integrada Digizl do Brasil ao Mitronésimo Rro de Janeiro FIBGE e IBGE 2001 Malha Digrtal co Brasil Rio de Jane ro FIBGE 
Os mega-resorts internacionais, além de contar com vários hotéis resort em suas instalações, situam-se em áreas litorâneas extensas, cercadas e muradas, que possuem mais de 100 hectares ${ }^{25}$. Nestas bolhas de consumo turístico global busca-se recriar "a cor e o clima local" de forma pitoresca e controlada como apregoa a propaganda da "Vila Nova da Praia" da Costa do Sauípe: "Aqui, a alegria de viver está expressa no rosto das quituteiras (...), nas fachadas das casas, nas lojinhas (...) $\mathrm{Na}$ Vila, conheça, também, o melhor do folclore e das artes baianas. Além disso, todas as noites há uma atração especialmente preparada para os hóspedes"26.

Tudo isso de modo a garantir uma experiência tropical única em um ambiente seguro e "inviolável", sem pedintes, sem odores estranhos, sem batedores de carteira, e com um "povo" limpo, educado e selecionado dentre a população da região metropolitana de Salvador. O "encontro", a "festa", marcas características do urbano (LEFEBVRE, 1969), são recriados de forma controlada e asséptica, transmutam-se em espetáculo monitorado e programado, em que os participantes convertem-se em atores e espectadores, que assistem e aplaudem..

Como se isso não bastasse, e talvez como uma forma de superar problemas interpostos por seu ciclo de vida (AGARWAL, 2002), e garantir-lhes maior durabilidade e rentabilidade, os resorts não se limitam mais a aparecer apenas como destinos exóticos de pacotes turísticos comercializados em agências de viagem de diversos países ao redor do mundo. Agora os resorts da Costa do Sauípe e da Reserva Imbassaí oferecem, além de um lugar para férias paradisíacas, a possibilidade de uma segunda residência em uma localização segura, cercada, exótica, dotada de serviços e conforto próprios de países de primeiro mundo. Aos quais se somam, através de um sistema pay per $u s e^{27}$, serviços domésticos característicos de países de terceiro mundo, como por exemplo, babá, empregada, cozinheira, etc., acessíveis no primeiro mundo apenas a pessoas de alto poder aquisitivo.

A propaganda da Reserva Imbassaí não deixa margem a dúvidas a quem se direciona seu empreendimento, ao salientar que "Para quem está em Portugal, a TAP disponibiliza, em parceria com a Varig, sete vôos semanais, um por dia, na rota Lisboa - Salvador/ Salvador - Lisboa. São apenas 8 horas de vôo até chegar

\footnotetext{
25. Segundo dados das páginas da internet e folhetos informativos, a Reserva Imbassaí (http:// www.reservaimbassai.com) conta com 132,73 hectares e a Costa do Sauípe (http:// www.costadosauipe.com) conta com 176 hectares

26. Acessível em http://www.costadosauipe.com.br/conteudo.php?secao=31\&idioma=1, em 12/2006. 27. Conforme informações prestadas pelos corretores entrevistados, em 12/2006, em ambos os empreendimentos, os condomínios situados no interior dos resorts fornecem todos os tipos de serviços, que são pagos conforme o uso que deles fazem os condôminos. Na Reserva Imbassaí uma firma de São Paulo (Itambé S.A,) é responsável pela administração e fornecimento destes serviços. $\mathrm{Na}$ Costa do Sauípe a administração do empreendimento possui um cadastro de funcionários preparados e qualificados para a prestação de serviços.
} 
ao paraíso"28 . O "paraíso" converte-se, assim, em objeto de consumo e é colocado em termos de tempo e dinheiro ao alcance dos moradores de vários países da Comunidade Européia, enquanto uma possibilidade de segunda residência.

O sucesso comercial é tamanho que, de acordo com os depoimentos de corretores imobiliários, entrevistados nos stands de vendas de condomínios fechados da Costa do Sauípe ${ }^{29}$ e da Reserva Imbassaí, cerca de $45 \%$ dos compradores são oriundos da Comunidade Européia, em sua maioria espanhóis, portugueses, ingleses e irlandeses, e pagam à vista. O que não é de espantar, uma vez que por duzentos mil euros, nas praias mediterrâneas da Espanha e Portugal, em particular no litoral da Catalunha, somente seria possível adquirir um apartamento de pequeno porte de cinquienta metros quadrados. Pois, desde a instauração da Comunidade Européia e da moeda comum (euro), os preços dos imóveis, nas densamente ocupadas localidades da costa mediterrânea espanhola e portuguesa, tornaram-se proibitivos, mesmo para os habitantes da Comunidade Européia. Enquanto nos condomínios dos resorts do litoral norte baiano, por este mesmo montante, é-lhes facultado adquirir casas de luxo em centro de terreno com quatro suítes, piscina, jardim, churrasqueira e área de lazer em mil metros quadrados privativos, entre outras amenidades. A que se soma, ainda, a possibilidade de aquisição de imóveis através de empresas imobiliárias estrangeiras ${ }^{30}$, que permite aos compradores estrangeiros obter financiamentos de longo prazo em seus países de origem, a juros inferiores aos vigentes no Brasil.

Ao iniciar o empreendimento da Reserva Imbassaí com o lançamento dos condomínios fechados, enquanto o resort e os hotéis encontram-se em construção, o grupo português Reta Atlântico S.A. seguiu o percurso inverso ao da Construtora Norberto Odebrecht e da Previ na Costa do Sauípe. Ai o lançamento dos condomínios "Casas de Sauípe" e "Quintas de Sauípe", totalmente vendidos, foi precedido pela implantação de hotéis-resort e de um complexo conjunto de equipamentos de lazer, entre os quais: um centro náutico, um centro poliesportivo, um centro de equitação e um campo de golfe ${ }^{31}$. Outros resorts, por sua vez, apresentam-se como centros de spa, como o Ecoresort da Praia do Forte e o Vila Galé Marés.

Aos mega-resorts preexistentes veio se somar o Iberostar resort (ver Mapa 2), no povoado da Praia do Forte, município de Mata de São João, nas vizinhanças do Projeto Tamar, implantado com recursos próprios da ordem de US\$ 370 milhões

\footnotetext{
28. Acessível em http://www.reservaimbassai.com/, em 12/2006

29. Acessível em http://www.costadosauipe.com.br, em 12/2006

30. Comercializado em Portugal pelo Grupo Garvetur (Acessível em http://www.garvetur-int.com/ imbassai/pt/) e na Inglaterra pelo Grupo Headlands (Acessivel em http://www.headlands.co.uk/06/ brazil bahia.asp/, em 12/2006).

31. Ver maiores informações na página do empreendimento acessível em http:// www.costadosauipe.com.br
} 
pela mega-corporação espanhola de mesmo nome, que permite aos seus usuários jogar golfe ao redor do mundo. Quando finalizado, em 2008, o Iberostar disporá de um centro de convenções e três hotéis, com 1.670 unidades de hospedagem ${ }^{32} \mathrm{e}$ seus hóspedes poderão contar com vôos fretados contratados pela Iberoworld, empresa aérea do grupo, e pela Condor da operadora inglesa Thomas Cook.

Além dos mega-resorts em Mata de São João, há outros de médio porte, como o Bahia Plaza Resort ${ }^{33}$ com 28 hectares e o Vila Galé Marés, ambos no município de Camaçari entre a praia de Guarajuba e o Rio Pojuca, limite natural com o povoado da Praia do Forte. Estaria prevista, ainda, a implantação, entre outros empreendimentos, do Resort Pojuca com doze hectares nas proximidades da foz do rio Pojuca (BAHIA, 2001).

Tais empreendimentos privados não teriam sido possíveis se não houvessem sido criadas condições gerais através de investimentos públicos. Contribuíram para isso a criação e implementação do Prodetur-NE, e o fato do estado da Bahia captar no âmbito deste programa um dos maiores volumes de investimentos turísticos do Brasil ${ }^{34}$. A tabela 2 mostra a distribuição dos investimentos públicos nas zonas turísticas, para o período de 1991-2020, em que se incluem a abertura e duplicação da "Linha Verde", a modernização do aeroporto internacional de Salvador e a implantação de infraestruturas de esgoto na Costa do Sauípe e na Praia do Forte. Cabe considerar, ainda, que parte dos investimentos realizados na Baia de Todos os Santos possui um rebatimento direto na Costa dos Coqueiros, dada sua acessibilidade e proximidade da região metropolitana de Salvador.

A Costa dos Coqueiros da Bahia emerge, assim, como um dos maiores focos de recepção do turismo internacional e como objeto privilegiado de investimentos

Tabela 2: BAHIA - INVESTIMENTOS PÚBLICOS EM ZONAS TURÍSTICAS (1991-2020)

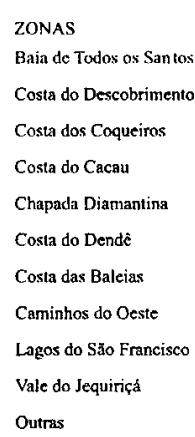

TOTAL GERAL

Fonte: SUINVEST, 2005. (acessivel em http://www.sct.ba.gov.br/prodetur.asp)
Em US\$ 1.000

\begin{tabular}{rr}
\hline EM EXECUÇĀO & EM PROJETO \\
53.698 & 288.150 \\
3.329 & 174.967 \\
2.329 & 140.300 \\
11.014 & 230.227 \\
10.859 & 205.439 \\
37 & 214.462 \\
90 & 172.412 \\
811 & 1.831 \\
93 & 907 \\
& 181.578 \\
3.625 & 1.610 .273 \\
\hline 85.885 &
\end{tabular}

TOTAL

1.236.211

324.263

271.216

350.825

323.653

283.142

217.504

8.242

6.343

869

329.022

3.351 .295 
“Yes, nós Temos Bananas!” Praias, Condomínios Fechados, Resorts e Problemas Sócio-ambientais

privados nacionais e estrangeiros em zonas turísticas do estado da Bahia, como se pode depreender dos dados da tabela 3 . Até 2005 , entre investimentos concluídos e em fase de execução foram despendidos aí quase quatrocentos e cinquienta milhões de dólares, equivalentes a 35,44\% do total investido no estado. Até 2020 a área das APAs Litoral Norte e Mangue Seco na Costa dos Coqueiros, que até 1996 abrigavam 28.985 habitantes (ver Tabela 1 ), devem receber investimentos privados da ordem de dois bilhões e meio de dólares, com uma previsão de alcançar 14.165 unidades de hospedagem, com capacidade de abrigar cerca de trinta mil hóspedes...

Tabela 3: BAHIA - INVESTIMENTOS PRIVADOS EM ZONAS TURÍSTICAS (1991 -2020)

\begin{tabular}{|c|c|c|c|c|c|c|c|c|}
\hline \multirow[t]{2}{*}{ ZONAS TURISTTICAS } & \multicolumn{2}{|c|}{ Concluído } & \multicolumn{2}{|c|}{ Execução } & \multicolumn{2}{|c|}{ Projeto } & \multicolumn{2}{|c|}{$\begin{array}{l}\text { Em US\$ } 1.000,00 \\
\text { Global }\end{array}$} \\
\hline & UH'S & US\$ & UH'S & USS & UH'S & US\$ & UH'S & USS \\
\hline Costa dos Coqueiros & 5.536 & 281.499 & 1.531 & 167.426 & 7.098 & 2.350 .519 & 14.165 & 2.799 .444 \\
\hline Baía de Todos os Santos & 6.037 & 258.412 & 621 & 41.067 & 2.261 & 600.515 & 8.919 & 899.994 \\
\hline Costa do Dendê & 2.153 & 29.146 & & & 700 & 443.000 & 2.853 & 472.146 \\
\hline Costa do Cacau & 3.447 & 78.622 & 94 & 41.200 & 5.530 & 779.000 & 9.071 & 898.822 \\
\hline Costa do Descobrimento & 8.609 & 277.946 & 60 & 5.000 & 4.086 & 1.368 .400 & 12.755 & 1.651 .346 \\
\hline Costa das Baleias & 2.506 & 51.201 & & & 572 & 298.450 & 3.078 & 349.651 \\
\hline Chapada Diamantina & 1.142 & 18.350 & 20 & 200 & 150 & 307.000 & 1.312 & 325.550 \\
\hline Outras & 1.145 & 16.545 & & & 0 & 288.000 & 1.145 & 304.545 \\
\hline TOTAL GERAL & 30.575 & 011.721 & 2.326 & 254.893 & 20.397 & 6.434 .884 & 53.298 & 7.701 .498 \\
\hline
\end{tabular}

As tabelas 2 e 3 indicam de forma inequívoca que os empreendimentos realizados até o momento constituem apenas o início de uma ocupação mais intensa do litoral norte baiano, principalmente ao se considerar o volume de investimentos previsto até 2020 .

Os mega-resorts internacionais na Costa dos Coqueiros na Bahia emergem, assim, como enclaves de riqueza e tecnologia em meio a um contexto regional empobrecido e sem infraestruturas e serviços. Não obstante tenham contribuído para:

impulsionar um desenvolvimento descentralizado das atividades de turismo antes polarizadas por Salvador e por Porto Seguro (Costa do Descobrimento)

gerar um volume significativo de empregos, como é o caso da Costa do Sauípe, que com suas 1.596 unidades de hospedagem responde por cerca de dois mil e quinhentos empregos diretos e vários empregos indiretos nas atividades de suporte;

32. Extraído de: http://oglobo.globo.com/boaviagemonline/aviacao/192246706.asp, acessado em $14 / 12 / 2006$.

33. Acessível em http://www.plazahoteis.com.br/bahia.htm, em 12/2006

34. Conforme informações do PRODETUR-BA - acessível em http://www.sct.ba.gov.br/prodetur.asp, acessado em 12/2006. 
modernizar e diversificar a estrutura produtiva da Costa dos Coqueiros.

No entanto, as benesses dos investimentos públicos e privados realizados, ainda não se fizeram sentir nos povoados litorâneos das APAs Litoral Norte e Mangue Seco da Bahia, por motivos de diversas ordens, que podem ser atribuídos:

a) às necessidades impostas para a reprodução do capital investido nos empreendimentos;

b) à condição de existência e modo de vida das comunidades atingidas e

c) à incapacidade das administrações municipais em regular os processos em curso.

Os habitantes dos pequenos povoados, ao serem tirados do isolamento em que viviam defrontaram-se com exigências para as quais não estavam preparados. Em boa parte devido ao nível de qualificação profissional exigido por parte dos mega-resorts a que se contrapõe o baixo índice de escolaridade da população local e as carências crônicas na oferta de educação pública. Em decorrência, os postos de empregos qualificados, que requerem domínio de idiomas e capacidade de administração, em todos os empreendimentos de porte internacional visitados, foram preenchidos com trabalhadores residentes na região metropolitana de Salvador, que se deslocam diariamente em transportes contratados pelas administrações dos empreendimentos. Assim, a muitos que sonhavam conseguir bons empregos e.melhorar de vida com a implantação dos resorts internacionais resta se conformar com uma inserção em postos de baixa qualificação e remuneração para prestação de serviços, em bases formais, nos resorts através do sistema pay per use ou como funcionários em instalações de hospedagem e de turismo de médio e pequeno porte, aos quais se somam as possibilidades de emprego, em bases formais e informais, nas residências situadas nos diversos condomínios da área.

Por outra parte o desenvolvimento do turismo e a diversificação das atividades econômicas ainda não se refletiram na arrecadação de tributos dos municípios, cujas principais fontes de recursos, em termos tributários, seriam os repasses do Governo Federal, do imposto sobre circulação de mercadorias e serviços do Governo Estadual e dos royalties pagos pela Petrobrás (IBGE, 2003). Embora esta situação tenda a mudar, em virtude do volume de atividades terceirizadas nos grandes empreendimentos.

\section{Você Já Foi à Bahia, nêga? Não! Pois então vá! ${ }^{35}$ Antes que acabe...}

Torna-se patente, assim, que o surto de empreendimentos empresariais de grande porte contribuiu para desagregar as relações tradicionais de produção pré-

35. Primeiros versos de uma canção de Dorival Caymmi intitulada "Você Já Foi a Bahia?" 
existentes ainda remanescentes, com a transformação de parte da população local em prestadores de serviço e assalariados no âmbito das atividades de serviços e turismo. $\mathrm{O}$ avanço da ocupação de caráter urbano com o cercamento de extensas áreas particulares e o redirecionamento de seu uso, embora facilitada pelo esvaziamento populacional prévio da área, não ocorre isenta de conflito, em particular devido ao cerceamento do acesso e uso dos recursos naturais em áreas de uso comunitário tradicional, a que a população local antes possuía livre acesso, ou em decorrência da presença massiva de operários da construção civil oriundos da região metropolitana.

A situação presente assemelha-se à calmaria antes da tempestade. Embora na última década tenham sido aprovados apenas seis novos loteamentos (BAHIA, 2001:25), entre 1970 e 1990, foram aprovados mais de setenta loteamentos, num total de cerca de vinte mil lotes com áreas entre seiscentos e mil e seiscentos metros quadrados, situados em sua maioria em áreas de restinga ou nos estuários dos rios que deságuam na costa (idem, p.24). Aproximadamente mil Sauípes. Este estoque de lotes e a pressão crescente dos setores imobiliário e turístico prenunciam uma nova fase de devastação ambiental na área das dunas costeiras, a despeito das restrições impostas pela legislação ambiental. Inclusive surgiram, recentemente, novos parcelamentos e construçōes irregulares nos povoados litorâneos de Entre Rios e Conde, em áreas sem saneamento. Isto ocorre seja pela falta de recursos e de pessoal capacitado das municipalidades em fazer cumprir a legislação e controlar as implantações, seja pelas características legais dos terrenos de marinha e seus acrescidos (BRASIL, Decreto-Lei 9.760/46).

Este quadro aponta para uma intensificação, no médio prazo, da ocupação de caráter urbano na Costa dos Coqueiros. É premente, pois, buscar definir ações que contribuam para minimizar os impactos ambientais e os conflitos sociais, e para melhorar as condições de vida da população local. Medidas ambientais de cunho geral, norteadoras de ações em escala nacional, ou medidas específicas com alcance local mostram-se ineficazes para conter o avanço da ocupação de caráter urbano com a segregação dos diferentes espaços, sem que se verifique uma efetiva melhoria das condições de vida dos habitantes dos pequenos povoados litorâneos.

Não obstante tenham sido tomadas, por parte do governo estadual, medidas diversas para regular e minimizar os impactos desta crescente ocupação da orla norte da Bahia, que compreendem a elaboração de diagnósticos (BAHIA, 2001), planos de gerenciamento costeiro (BAHIA, 2003), inserção do município de Conde no Projeto Orla (PREFEITURA MUNICIPAL DE CONDE, 2004), e um projeto de ordenamento territorial (BAHIA, 2005), a tendência é a intensificação do crescimento urbano e do turismo, em particular nas áreas de estuários e restingas, com um aprofundamento da segregação sócio-espacial e das diferenças. Enquanto os grandes empreendedores usufruem as externalidades geradas pelos investimentos 
públicos e têm acesso a diversas fontes de financiamento, a incentivos fiscais e financeiros, graças às parcerias público privadas implementadas com recursos do governo federal e estadual, a população local é alijada destes investimentos e segue vivendo com uma oferta precária de serviços, infraestruturas físicas e sociais.

A análise dos planos e estudos elaborados para a área revela um equívoco estratégico crucial. Quase todos os estudos partilham uma excessiva ênfase no desenvolvimento urbano e uma preocupação em definir um plano de zoneamento para cada município em conformidade com as tipologias do Projeto Orla, ainda que muitas das áreas já loteadas sequer se encontrem ocupadas e não apresentem tendências à densificação. Todavia, nenhum destes planos e estudos se preocupa em questionar a dispersão territorial dos loteamentos ao longo da Costa dos Coqueiros e em propor uma solução alternativa.

A dispersão aparentemente é aceita pelos órgãos estaduais, pelos agentes e atores sociais como um fato dado e consumado. Um indicador dessa postura são os parâmetros urbanísticos definidos pelo Zoneamento Econômico e Ecológico da APA-Litotal Norte, segundo os quais os lotes devem ter no mínimo 250 metros quadrados. Ao mesmo tempo em que esta medida contribui para prevenir uma verticalização e densificação massiva extensiva na área tende a impulsionar a dispersão da ocupação e a coibir o acesso da população de baixa renda aos terrenos da área.

Todos os planos, propostas e ações participativas implementadas na APA Litoral Norte, assim, ao invés de discutir possíveis estratégias e soluções alternativas, como por exemplo a formação de aglomerações densas em determinados pontos da costa, de modo a permitir a preservação dos vários ecossistemas existentes entre elas, como propõe por exemplo o plano diretor urbanístico do sistema costeiro da Catalunha (CATALUNYA, 2006 e NELLO, 2006), conjugam a preservação ambiental com a dispersão urbana e se empenham em repartir o território em zonas diferenciadas de urbanização. Optam assim por uma extensificação e não por uma intensificação da urbanização (LIMONAD, 2006) em pontos selecionados da costa.

O que é notável, em um país de recursos limitados como o Brasil, ainda mais ao se tomar em consideração as ingerências em diversos países da Comunidade Européia para conter a dispersão da urbanização em particular nas orlas litorâneas (ver a respeito FONT, INDOVINA e PORTAS, 2005), como é o caso da costa mediterrânea espanhola, devido aos desafios que se impõe para a gestão urbana (FREGOLENT, 2006), em razão dos impactos ambientais e do ônus para a extensão territorial das redes de infraestrutura e serviços.

A este equivoco estratégico soma-se a opção, consubstanciada na Constituição de 1988 e fundamentada pelo Projeto Orla (BRASIL, 2004), pela escala municipal para a gestão dos problemas ambientais. A opção desta escala revela-se inadequada, primeiro, pelo simples fato de que os problemas ambientais 
não terminam nos limites municipais; em segundo lugar por que muitas das administrações municipais envolvidas carecem não só de recursos, mas de se conscientizar de sua responsabilidade ambiental e, em terceiro lugar, necessitam superar a visão de que ocupação é igual a desenvolvimento. São necessárias, assim, ações de conscientização e atualização das administrações municipais de modo a capacitá-las a estabelecer medidas administrativas e tributárias de estímulo à conservação ambiental e a arrecadar os impostos de modo a ter recursos para fiscalizar e fazer cumprir a legislação de uso do solo e de conservação ambiental.

Os problemas que ora se impõem ultrapassam a escala local-municipal, e somente poderão ser superados mediante ações articuladas entre os diversos municípios de modo a desenvolver uma base comum de gestão ambiental em escala regional, com uma efetiva participação dos distintos atores e agentes envolvidos. Embora os planos e ações anteriores contemplassem formas de participação e envolvimento da população ao nível local (BAHIA, 2001), de modo a capacitar e envolver a população nas soluções implementadas, estas ações seguiram modelos em que apenas os representantes de determinados setores participaram. E, como se mencionou acima, se nem os planos e modelos questionaram a dispersão, o que dizer dos comitês locais. Uma efetiva participação no processo de planejamento exige que se discutam não apenas questões táticas e operacionais, mas questões estratégicas. Caso contrário esta participação serve mais para legitimar o processo de planejamento do que para compatibilizar os diferentes interesses envolvidos.

A ausência de mecanismos efetivos e transparentes de participação da população e dos municípios no desenvolvimento regional, assim, aparentemente é um dos principais problemas a ser enfrentado, cuja solução reside em ações em diferentes esferas e escalas. Na escala local e na esfera do cotidiano e da reprodução social da população são necessárias ações educativas afirmativas e de conscientização da população com relação aos processos em curso e à importância de sua participação efetiva em fóruns locais e regionais. $\mathrm{Na}$ escala regional e da reprodução dos meios de produção urge criar instâncias e mecanismos de participação, como por exemplo consórcios e fóruns regionais que congreguem os municípios envolvidos, de modo a gerar uma arena de discussão em que os diversos atores envolvidos possam se enfrentar e discutir soluções conjuntas. Pois o planejamento da participação no planejamento através de uma estrutura administrativa rígida e um número pré-definido de participantes tende a servir mais para legitimar propostas do Estado e dos empreendedores do que para permitir uma efetiva participação dos envolvidos.

Urge, pois, colocar questões de fundo estratégico na pauta regional de discussão, com vistas a optar por uma intensificação ou extensificação da urbanização na área, pari passu a uma definição mais extensa e estrita, em escala regional, das áreas de preservação, de modo que os loteamentos aprovados e não ocupados se adequem às mudanças legais propostas, e não vice-versa, que as áreas de preservação sejam definidas a partir dos loteamentos aprovados. 
Resumo: A proliferação de condomínios, resorts e clubes turísticos na orla do litoral brasileiro, e o aumento do turismo internacional, contribuíram para converter em objeto de consumo várias partes da costa brasileira, acarretando uma expansão geográfica indiscriminada das atividades de turismo e veraneio, que colocam em risco a diversidade de um dos mais ricos conjuntos de ecossistemas costeiros tropicais do mundo. A intenção deste ensaio é levantar a extensão e as características da ocupação costeira relacionadas à multiplicação de condomínios, resorts e aglomerados urbanos em um trecho específico da orla litorânea do Nordeste do Brasil: a Costa dos Coqueiros ao norte da região metropolitana de Salvador na Bahia, com a meta de fazer algumas breves considerações sobre os impactos sócio-ambientais resultantes, bem como propor elementos que subsidiem ações integradas de planejamento e desenvolvimento regional para a área.

Palavras-chave: Turismo, Resorts, Bahia, Planejamento Regional, Desenvolvimento Local.

\section{"YES, WE HAVE BANANAS!": BEACHES, GATED COMMUNITIES, RESORTS ANDSOCIO-ENVIRONMENTALISSUES}

Abstract: The proliferation of gated communities, resorts and tourism clubs on Brazil's coastline area, besides the international tourism increase, had contributed to convert many seaside places into consumption objects, bringing along an indiscriminate geographic expansion of tourism activities, jeopardizing the diversity of one of the world's richest tropical coastal ecosystems. This paper intends to verify the extension and characteristics of the coastal occupation related to gated communities concerning the multiplication of condominiums, resorts and urban agglomerations in a specific part of Brazil's northeastern littoral area: the "Coconut Coast" on the north of Salvador metropolitan area, in Bahia, with goal to make some brief remarks on the ensuing social and environmental impacts, as well to consider ways to subsidize regional development and integrated planning actions on this area.

Keywords: Seaside Tourism Development, Resorts, Bahia, Regional Planning, Local Development.

\section{BIBLIOGRAFIA}

AGARWAL, S. 2002. Restructuring Seaside Tourism. Annals of Tourism Research, Vol. 29, $\mathrm{N}^{\circ} 1$, pp. 25-55.

BAHIA. 2003. GERCO - Litoral Norte - Projeto de Gerenciamento Costeiro. Revisão do Diagnóstico Sócio-Ambiental, Consolidado numa Proposta de Zoneamento e Plano de Gestão. Salvador: Governo do Estado da Bahia - Secretaria de Meio Ambiente e Recurso Hídricos/ Centro de Recursos Ambientais.

2005. Plano de Desenvolvimento e Ordenamento Territorial das Povoações Litorâneas da APA do Litoral Norte do Estado da Bahia. Salvador: 
"Yes, nós Temos Bananas!" Praias, Condomínios Fechados, Resorts e Problemas Sócio-ambientais

Governo do Estado da Bahia - Secretaria de Meio Ambiente e Recurso Hídricos/ Centro de Recursos Ambientais.

BERTONCELLO, R.V. 1992. Processo de Modernização e Espaço Local: $o$ caso do município de Angra dos Reis (RJ). Rio de Janeiro: dissertação de mestrado, IGEO/UFRJ.

BNDES. 1999. PRODETUR: Infra-estrutura e seus reflexos no turismo. Rio de Janeiro: BNDES - Governo Federal.

BRASIL. 2002. Avança Brasil - Programas Estratégicos: Relatório de Situação. Brasília: Governo Federal. 1946. Decreto-Lei 9.760/46 - Dispõe sôbre os bens imóveis da União e dá outras providências. Brasília: Presidência da República - Governo Federal. 05/09/1946.

. 1988. Lei 7.661 - Programa Nacional de Gerenciamento Costeiro (GERCO). Brasília: Ministério do Meio Ambiente - Governo Federal, 16/ $05 / 1988$.

2004. Projeto Orla. Brasília: Ministério do Meio Ambiente - Governo Federal.

CATALUNYA . 2006. Amb Vistes al Mar - Pla Director Urbanístic del Sistema Costaner: Un Pla per preservar el litoral. Barcelona: Generalitat de Catalunya - Departament de Política Territorial i Obres Publiques.

COSTA, H.S.M. et al. (org.) 2006. Novas Periferias Metropolitanas - a expansão metropolitana em Belo Horizonte: dinâmica e especificidade no eixo Sul. Belo Horizonte:C/Arte e Fapemig.

FREGOLENT, L. 2005. Governare la dispersione. Milano: Franco Angeli.

FONT, A.; INDOVINA, F. e PORTAS, N. 2005. L'Explosione della Città. Provinzia de Bologna: Università IUAV di Venezia / Editrice Compositori.

IBGE. 2003. O Brasil, município por município. Rio de Janeiro: FIBGE. LEFEBVFRE, H. 1969. O Direito à Cidade. São Paulo: Documentos.

LIMONAD, E. 1996. Os Lugares da Urbanização. São Paulo: tese de doutorado

FAUUSP. (acessível em http://www.teses.usp.br/teses/disponiveis/16/ $16131 /$ tde-27042005-162418/).

2006. Nem tudo acaba em Los Angeles. Anais do $52^{\circ}$ Congreso Internacional de Americanistas. Sevilla: Universidad de Sevilla (mimeo). MONTE-MÓR, R.L.M. 1994. Urbanização extensiva e lógicas de povoamento: um olhar ambiental. in SANTOS, M., SOUZA, M.A.S. e SILVEIRA, M.L. (org.) Território: Globalização e Fragmentação. São Paulo: Hucitec Anpur.

MORAES, A.C.R. 2004. Classificação das Praias Brasileiras por níveis de 
ocupação. In BRASIL. Projeto Orla-Subsídios para um Projeto de Gestão. Brasília: Ministério do Meio Ambiente - Governo Federal. v.3

NEL-LO, O. 2006. La nova política territorial de Catalunya. Barcelona: Generalitat de Catalunya - Secretari per a la Planificació Territorial.

PREFEITURA MUNICIPAL DE CONDE. 2004. Projeto Orla - Plano de Intervenção na Orla Marítima do Município de Conde-BA. Conde: GERCO/SPU/IBAM/MMA. 